Open Access

\title{
Effects of different arachidonic acid supplementation on psychomotor development in very preterm infants; a randomized controlled trial
}

Ayham Alshweki ${ }^{1 *}$, Alejandro Pérez Muñuzuri ${ }^{1}$, Ana M. Baña ${ }^{1}$, Ma. José de Castro ${ }^{1}$, Fernando Andrade², Luís Aldamiz-Echevarría², Miguel Sáenz de Pipaón ${ }^{3}$, José M. Fraga and María L. Couce ${ }^{1}$

\begin{abstract}
Background \& aims: Nutritional supplementation with polyunsaturated fatty acids is important in preterm infants neurodevelopment, but it is not known if the omega-6/omega-3 ratio affects this process. This study was designed to determine the effects of a balanced contribution of arachidonic acid in very preterm newborns fed with formula milk.

Methods: This was a randomized trial, in which newborns $<1500 \mathrm{~g}$ and/or $<32$ weeks gestational age were assigned to one of two groups, based on the milk formula they would receive during the first year of life. Initially, 60 newborns entered the study, but ultimately, group A was composed of 24 newborns, who were given formula milk with an $\omega-6 /$ $\omega-3$ ratio of 2/1, and Group B was composed of 21 newborns, given formula milk with an $\omega-6 / \omega-3$ ratio of 1/1. The infants were followed up for two years: growth, visual-evoked potentials, brainstem auditory-evoked potentials, and plasma fatty acids were periodically measured, and psychomotor development was assessed using the Brunet Lézine scale at 24 months corrected age. A control group, for comparison of Brunet Lézine score, was made up of 25 newborns from the SEN1500 project, who were fed exclusively with breast milk.
\end{abstract}

Results: At 12 months, arachidonic acid values were significantly higher in group A than in group B $(6.95 \pm 1.55 \%$ vs. $4.55 \pm 0.78 \%)$, as were polyunsaturated fatty acids (41.02 $\pm 2.09 \%$ vs. $38.08 \pm 2.32 \%)$ achieved a higher average. Group A achieved a higher average Brunet Lézine score at 24 months than group B $(99.9 \pm 9$ vs. $90.8 \pm 11, p=0.028)$. The Brunet Lézine results from group A were compared with the control group results, with very similar scores registered between the two groups $(99.9 \pm 9$ vs. $100.5 \pm 7$ ). There were no significant differences in growth or evoked potentials between the two formula groups.

Conclusions: Very preterm infants who received formula with an $\omega-6 / \omega-3$ ratio of $2 / 1$ had higher blood levels of essential fatty acids during the first year of life, and better psychomotor development, compared with very preterm newborns who consumed formula with an $\omega-6 / \omega-3$ of $1 / 1$. Therefore, formula milk with an arachidonic acid quantity double that of docosahexaenoic acid should be considered for feeding very preterm infants.

Trial registration: ClinicalTrials.gov Identifier NCT02503020.

Keywords: Lipids, Nutrition, Arachidonic acid, Omega-6/Omega-3 Ratio, Preterm infants, Psychomotor development

\footnotetext{
* Correspondence: drayham@live.com

${ }^{1}$ Neonatology Unit, Department of Paediatrics, University Clinical Hospital of Santiago de Compostela. IDIS, CIBERER, Travesia Choupana, 15706, Santiago de Compostela, Spain

Full list of author information is available at the end of the article
}

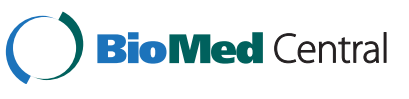

(c) 2015 Alshweki et al. Open Access This article is distributed under the terms of the Creative Commons Attribution 4.0 International License (http://creativecommons.org/licenses/by/4.0/), which permits unrestricted use, distribution, and reproduction in any medium, provided you give appropriate credit to the original author(s) and the source, provide a link to the Creative Commons license, and indicate if changes were made. The Creative Commons Public Domain Dedication waiver (http://creativecommons.org/publicdomain/zero/1.0/) applies to the data made available in this article, unless otherwise stated. 


\section{Background}

Long-chain polyunsaturated fatty acids (LCPUFAs), arachidonic acid (AA omega-6; 20:4 $\omega-6$ ), and docosahexaenoic acid (DHA omega-3; 22:6 $\omega-3$ ), are required for the formation of non-myelinated cell membranes in the central nervous system, including in the retina $[1,2]$, hence their great importance in appropriate visual and cognitive development. LCPUFAs are transferred from mother to foetus mainly during the last trimester of pregnancy $[2,3]$. At that time, and in the early neonatal period, sufficient levels of DHA and AA are required for the rapid synthesis of brain tissue, cellular differentiation, and active synaptogenesis $[4,5]$. In premature infants, this crucial supply is interrupted and they exclusively depend on breast milk and other exogenous sources [5]. Moreover, very-low-birth-weight (VLBW) and very preterm infants are particularly vulnerable to LCPUFAs deficiency, given the virtual absence of adipose tissue at birth, the potential immaturity of fatty acid elongation/desaturation pathways, and inadequate fatty acid intake from formula milk if not breast fed [6].

Arachidonic acid is the most abundant $\omega-6$ LCPUFA, and DHA is the most biologically important $\omega-3$ LCPUFA in breast milk [7]. The ratio of AA to DHA in human milk is usually $1.5-2 / 1$, but the variability is high, and the ratio is primarily determined by the habitual diet of the region or country $[8,9]$. The nutritional requirements for LCPUFAs in preterm newborns are not clearly established, because optimal LCPUFA blood levels and accretion rate are not well known $[10,11]$.

It has been reported that newborns fed with DHA- and AA-supplemented formula had higher Bayley mental and psychomotor development scores, with no increase in morbidity or adverse events [12]. Likewise, other studies in term and preterm infants considered formulas containing DHA to be more appropriate, because of the frequent deficiency of DHA in the first days of life in VLBW infants $[13,14]$. However, it must be remembered that AA is also a key component of cell membranes and is one of the most abundant fatty acids in the brain: it helps maintain hippocampal cell membrane fluidity [15], protects the brain from oxidative stress by activating peroxisome proliferator-activated receptor gamma [16], and activates syntaxin-3 (STX-3), a protein involved in the growth and repair of neurons [17]. In one study, term infants who were given supplemental AA showed significant improvements in intelligence, as measured with the Mental Development Index [18]. The dietary balance between $\omega-6$ and $\omega-3$ and their LCPUFA metabolites is likely to be important in humans of all ages, but perhaps even more so in preterm infants $[19,20]$.

Almost all preterm infant formulas contain AA supplementation. However, the formulas often contain an $\omega-6$ to $\omega-3$ ratio of $1 / 1$. This study aimed to clarify the importance of higher formula AA values and establish the preferred omega-6/omega-3 ratio for supplementation of breast milk, by assessing anthropometric, visual, auditory, and psychomotor development in very preterm infants receiving diets supplemented with different AA/ DHA ratios (1/1 vs. 2/1).

\section{Patients and methods \\ Study design}

This prospective randomized controlled double-blind trial was conducted to study nutritional supplementation in preterm infants $<1500 \mathrm{~g}$ and/or between 25-32 weeks gestational age (GA) who were born at the University Clinical Hospital of Santiago de Compostela (CHUS). The infants were enrolled for a period of 14 months (from July 2011 to August 2012) and followed up from birth until 2 years of age. Milk formulas were provided either as adjunct to insufficient breast milk quantity or as full formula feeding. Breastfeeding was actively encouraged. Patients were randomly assigned to one of the two formula groups, according to the type of formula they were to receive. The group A formula was supplemented with AA and DHA with an $\omega-6 / \omega-3$ ratio of $2 / 1$. The group $B$ formula was supplemented with AA and DHA with an $\omega-6 / \omega-3$ ratio of $1 / 1$. The primary outcome was psychomotor development, assessed with the Brunet Lézine scale at 2 years of age (Early Care Unit, CHUS). The secondary outcomes were plasma levels of fatty acids at 3 months, 6 months, and 12 months (Metabolic Unit, Cruces Hospital, Bilbao); visual- and auditory-evoked potentials at 6 and 12 months of age (Neurophysiology Unit, CHUS); and anthropometric measurements (weight, length, and head circumference) at 3, 6, 9, 12, 18, and 24 months of age (Neonatology Unit CHUS).

The Brunet Lézine assessment results from the 2 sample groups were compared with the results from 25 preterm infants $(<1500 \mathrm{~g})$ from the same hospital (CHUS) who were fed exclusively with human milk. Information was used from the $<1500 \mathrm{~g}$ preterm data registry of the Spanish Society of Neonatology (SEN 1500). This program includes 62 hospitals and centres throughout Spain, CHUS being one of them. The 25 most recently-born preterm infants $(<1500 \mathrm{~g})$ who were exclusively breast-fed were chosen. There was no human milk bank available, therefore all infants were fed with their own mother's milk.

\section{Power calculation and randomization}

The primary outcome of the study was psychomotor development. Differences in the Brunet Lezine score were expected; therefore, the sample size was calculated on this parameter using Brunet Lezine score results from the SEN 1500 study over 9 years (from 2003 to 2011). The absolute effect size was estimated for comparison between formula- and human milk-fed children: it was 
7.2 points. The sample size was 30 infants in each group, achieving an observed power of $80 \%$. The double-blind randomized allocation of infants to a study formula was stratified for gender, and a block size of four was applied. The researcher that generated the random allocation sequence was not the same researcher that enrolled participants and assigned participants to interventions. Participants and investigators were blinded to formula allocation until all data analysis had been performed.

\section{Study population}

During the data collection period, 3357 infants were born in our Hospital, of which 61 weighed $<1500 \mathrm{~g}$ and/ or were 25-32 weeks GA. One child was excluded during the first week due to a severe malformation; all other parents gave consent to participate in the study (30 infants in each group). Patients in the following situations were excluded: preterm infants with severe malformations, preterm infants with severe intraventricular haemorrhage or periventricular leukomalacia (more than grade 2), and neonates who did not need supplementary milk nutrition, i.e. breast-fed only children.

Sixty preterm infants entered the study in the first week of age. One died at 2 months, and communication was lost with two more: one at 3 months and the other at 6 months of age. Three preterm infants were excluded during their first two months because of severe intraventricular haemorrhage, and nine children converted to exclusive breastfeeding during the first six months. From 6 months until the end of the study, 45 children were included and followed up: 24 infants in group A and 21 in group B.

\section{Ethical statement}

The study was approved by the Galician Research Ethics Committee, Spain. Written informed consent was obtained from all parents, after the experimental protocol had been explained to them in detail. The study was registered at ClinicalTrials.gov (NCT02503020).

\section{Dietary intervention}

Breastfeeding was encouraged in all preterm infants. Neonates who could not meet more than half their milk requirements from their mothers' milk alone at the end of the first week of age were included in the study. Infants in group A received milk formula for preterm infants containing a fixed amount of $\omega-3$ (DHA) lipids (0.33\%) with an $\omega-6 / \omega-3$ ratio of $2 / 1$. Infants in group $B$ received formula for preterm infants containing a similar quantity and quality of proteins, carbohydrates, lipids, vitamins, and micronutrients as group $\mathrm{A}$, and a fixed amount of $\omega-3$ lipids $(0.37 \%)$ but with an $\omega-6 / \omega-3$ ratio of $1 / 1$. It should be noted that neither of the formulas used contained other sources of $\omega-6$ and $\omega-3$ besides AA and
DHA, therefore when this study refers to the $\omega-6 / \omega-3$ ratio, it is equivalent to the AA/DHA ratio. Whilst in hospital, the two groups received similar quantities of fluids and calories (almost $160 \mathrm{ml} / \mathrm{kg} /$ day of fluids, and $120 \mathrm{kcal} / \mathrm{kg} /$ day), and a breast milk fortifier that did not contain lipids. At 3 and 6 months of corrected age, the milk type was changed according to nutritional requirements, but the same $\omega-6 / \omega-3$ ratio was maintained in each group. Parents began adding complementary foods at five months of life. They kept a daily nutrition diary, and the omega-6/omega-3 ratio in foods was strictly controlled so that the two groups received similar amounts of both omega- 6 and omega- 3 apart from the formula. The families of all children in both groups were given the same recommendations and encouraged to introduce complementary foods together with milk. Table 1 presents the main contents of the formulas used in this study [21].

\section{Methods}

For fatty acid analysis, blood samples were collected from study children at 1 week of age, then at 3, 6, and 12 months. The samples were collected in tubes with anticoagulant (EDTA). After immediate centrifugation the plasma was separated and stored at $-80{ }^{\circ} \mathrm{C}$ until analysis. When all samples had been received in the laboratory, plasma total fatty acids were trans-methylated as per the method described by Lepage and Roy [22]. Using tridecanoic acid as the internal standard, the fatty acid methyl esters were separated and quantified on an Agilent Technologies 7890A gas chromatograph using a flame ionization detector on a capillary column SP-2380 (Supelco, Bellefonte, PA, USA). Fatty acids were identified by comparison with commercial standards from $\mathrm{Nu}-$ Chek (Elysian, MN, USA) and Sigma (Madrid, Spain). Each fatty acid was quantified using electronic integration in the offline Chem Station. Nutritional content was calculated using a dietary calculation computer programme (www.odimet.es).

Anthropometric assessment was performed by the same personnel and with the same devices for both groups. For weight, a special balance was used (Seca), which had two programs: one with an expected error of $3 \mathrm{~g}$ and minimum and maximum limits of $40 \mathrm{~g}-6000 \mathrm{~g}$, respectively, (used until 3 months of age) and the other program with an expected error of $5 \mathrm{~g}$ and minimum and maximum limits of $100 \mathrm{~g}-15000 \mathrm{~g}$, respectively, (used for infants older than 3 months). Length was measured using a special sliding infant measuring table (counter recording) with an expected error of $2 \mathrm{~mm}$ and a minimum and maximum of $20 \mathrm{~cm}$ and $100 \mathrm{~cm}$, respectively (Holtain). Head circumference was determined using a non-stretchable measuring tape, measuring the perimeter 
Table 1 Total proteins, lipids, and carbohydrate per $100 \mathrm{ml}$ of formula used

\begin{tabular}{|c|c|c|c|c|}
\hline \multicolumn{2}{|c|}{ Compositions of $100 \mathrm{ml}$ of used formulas } & \multirow{2}{*}{$\frac{\text { Total proteins } \mathrm{g} / 100 \mathrm{ml}}{2.35}$} & \multirow{2}{*}{$\begin{array}{l}\text { Total lipids } \mathrm{g} / 100 \mathrm{ml} \\
4\end{array}$} & \multirow{2}{*}{$\frac{\text { Total carbohydrates } \mathrm{g} / 100 \mathrm{ml}}{8.64}$} \\
\hline Group A formula $(\omega-6 / \omega-3=2)$ & Preterm formula (16 \%) & & & \\
\hline & First 6 months formula (13\%) & 1.43 & 3.77 & 7.15 \\
\hline & 6-12 months formula (13\%) & 1.65 & 2.92 & 7.67 \\
\hline \multirow[t]{3}{*}{ Group B formula $(\omega-6 / \omega-3=1)$} & Preterm formula (16 \%) & 2.27 & 4.22 & 8.51 \\
\hline & First 6 months formula (13\%) & 1.52 & 3.57 & 7.67 \\
\hline & 6-12 months formula (13\%) & 1.61 & 3.09 & 7.52 \\
\hline \multirow[t]{2}{*}{ Human milk (22) } & Born $<29$ weeks GA & 2.2 & 4.4 & 7.6 \\
\hline & Born 32-33 weeks GA & 1.9 & 4.8 & 7.5 \\
\hline$p$ value & & ns & ns & ns \\
\hline
\end{tabular}

[22], Bauer et al. [21]; $13 \%$ and $16 \%$, the concentration of the formula ( $/ 100 \mathrm{cc}$ ). Significant differences between groups ( $p<0.05$, Kruskal-Wallis test)

at the level of the occipital prominence at the back and the mid forehead at the front.

Evoked potentials were performed using the same technique and device in both groups (Nicolet Viking IV $\mathrm{NT}$ ), and the results were evaluated by the same trained personnel. Psychomotor development was assessed using the Brunet Lézine Scale. The Brunet Lezine scale provides an objective evaluation of a child's maturation level in four areas: motor, coordination, language, and social [23]; an overall score $\geq 85$ is considered normal.

\section{Study of other risk factors}

It was important to establish if there were differences between group A and group B in terms of risk factors that could affect mental development. Therefore, sex, gestational age (assessed by prenatal echo), birth weight, APGAR, use of surfactant, sepsis, need for mechanical ventilation, use of $\mathrm{FiO} 2>30 \%$, presence of intracranial haemorrhage, administration of ibuprofen for patent ductus arteriosus, and presence of bronchopulmonary dysplasia were assessed in all children who entered the study. Finally, parents were asked if they worked, and if they had a university degree. The two groups were compared, and no significant differences were found between them (Table 2).

\section{Statistical analysis}

All statistical calculations were performed with SPSS (SPSS, v.20.0, Chicago, Illinois, USA). Normality of data

Table 2 Comparison of risk factors in children between the three groups

\begin{tabular}{|c|c|c|c|c|}
\hline \multirow[t]{4}{*}{ Some risk factors } & $\omega-6 / \omega-3=2$ & $\omega-6 / \omega-3=1$ & Control group & \multirow[t]{4}{*}{$p$ value } \\
\hline & Group A & Group B & & \\
\hline & $n=24$ & $n=21$ & \multirow{2}{*}{$\begin{array}{l}n=25 \\
\mathrm{n} \text { (rate) }\end{array}$} & \\
\hline & $\mathrm{n}$ (rate) & n (rate) & & \\
\hline Male & $12(50 \%)$ & $11(52 \%)$ & $12(48 \%)$ & ns \\
\hline Gestation age $<30$ weeks & $7(29 \%)$ & $7(33 \%)$ & $8(32 \%)$ & ns \\
\hline Weight at birth < 1000gm & $5(21 \%)$ & $4(19 \%)$ & $5(20 \%)$ & ns \\
\hline APGAR at 5 min $<9$ & $5(21 \%)$ & $4(19 \%)$ & $4(25 \%)$ & ns \\
\hline APGAR at $10 \min <9$ & $2(8 \%)$ & $2(10 \%)$ & $3(12 \%)$ & ns \\
\hline Need of surfactant & $8(33 \%)$ & $8(38 \%)$ & $8(32 \%)$ & ns \\
\hline Sepsis $^{a}$ & $4(17 \%)$ & $4(19 \%)$ & $5(20 \%)$ & ns \\
\hline Mechanical ventilation & $9(38 \%)$ & $6(29 \%)$ & $8(32 \%)$ & ns \\
\hline Need of Fio2 > $30 \%$ & $9(38 \%)$ & $7(33 \%)$ & $6(24 \%)$ & ns \\
\hline Intra cranial hemorrhage (grade I or II) & $3(13 \%)$ & $3(14 \%)$ & $4(16 \%)$ & ns \\
\hline Need of ibuprofen & 7 (29 \%) & $7(33 \%)$ & $7(28 \%)$ & ns \\
\hline Broncho pulmonary dysplasia ${ }^{b}$ & $2(8 \%)$ & $1(5 \%)$ & $1(4 \%)$ & ns \\
\hline Both parents do not have job & $2(8 \%)$ & $1(5 \%)$ & $2(8 \%)$ & ns \\
\hline Both parents do not have university degree & $13(54 \%)$ & $12(57 \%)$ & $12(48 \%)$ & ns \\
\hline
\end{tabular}

Data are presented as number (percentage), significant differences between groups ( $p<0.05$, Chi-square test)

${ }^{a}$ Preterm infants who had positive blood culture with appropriate clinical suspected status

${ }^{b}$ Preterm infants who had oxygen requirement either at 28 postnatal days or 36 weeks postmenstrual age 
was analyzed with the Shapiro-Wilk test. A $p$ value $<0.05$ was considered statistically significant (two-tailed test), with $95 \%$ confidence interval. Multiple testing corrections were performed using Bonferroni correction. Qualitative variables were compared between groups using a chisquare test. To evaluate Brunet Lezine score, Wilcoxon test was performed between each pair of groups (A and $\mathrm{B}, \mathrm{A}$ and control, and $\mathrm{B}$ and control). For plasma fatty acid values and anthropometric measurements, quantitative variables were compared between groups using Wilcoxon test.

\section{Results}

Sixty-one infants were recruited (Fig. 1), and 60 infants were randomly assigned to one of the two study formulas. Forty-five infants were followed up until 24 months of age.

During the first month of life, 54 of group A and $48 \%$ of group B were fed on breast milk supported with one of the formulas. At 3 months of chronological age, 79 of group A and $76 \%$ of group B were fed exclusively on formula, and at 6 months, 92 of group A and $86 \%$ of group $B$ were fed exclusively on formula. The percentage of feeds provided by breast milk in all mixed-fed infants was less than $40 \%$ of total milk (Group A, mean $21 \%$, (range $10 \%$ to $35 \%$ ). Group B, mean $26 \%$, (range $15 \%$ to $40 \%)\}$. There were no statistically significant differences between the two groups.

\section{Psychomotor development}

At 24 months' corrected age, the three groups were assessed using the Brunet Lézine scale. The proportion of preterm infants with a Brunet Lézine score greater than or equal to 85 was studied and compared, as was the mean score of each group, and a significant difference was noted (Table 3). Each group was then compared with the two other groups separately. There was a significant difference between group $\mathrm{A}$ and group B:
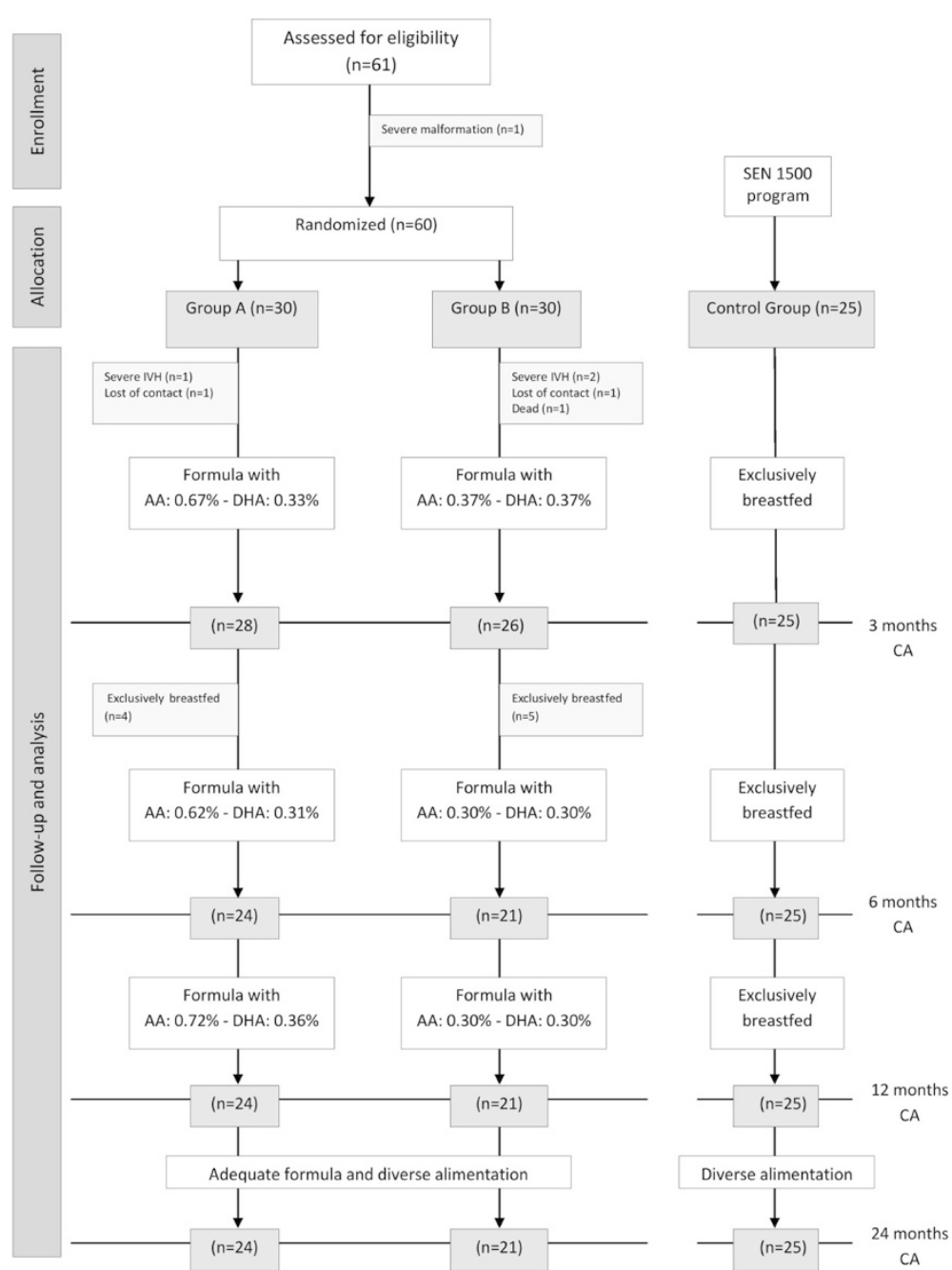

Fig. 1 Dietary intervention and follow-up of children during the first two years of life. CA, corerected age; IVH, intraventricular hemorrhage 
Table 3 Comparison of Brunet Lézine score in very preterm infants in group A, B, and control

\begin{tabular}{|c|c|c|c|c|c|c|c|c|c|}
\hline $\begin{array}{l}24 \text { months } \\
\text { Brunet-Lézine score }\end{array}$ & $\begin{array}{l}\omega-6 / \omega-3=2 \\
\text { Group A } n=24\end{array}$ & $\begin{array}{l}\omega-6 / \omega-3=1 \\
\text { Group B } n=21\end{array}$ & $p$ value & $\begin{array}{l}\text { Control group } \\
n=25\end{array}$ & $\begin{array}{l}\omega-6 / \omega-3=2 \\
\text { Group A } n=24\end{array}$ & $p$ value & $\begin{array}{l}\text { Control } \\
\text { group } n=25\end{array}$ & $\begin{array}{l}\omega-6 / \omega-3=1 \\
\text { Group B } n=21\end{array}$ & $p$ value \\
\hline Mean (SD) & 99.9 (9) & $90.8(11)$ & 0.028 & $100.5(7)$ & 99.9 (9) & ns & $100.5(7)$ & $90.8(11)$ & 0.007 \\
\hline$<85$ & 1 (4.2\%) & $6(28.6 \%)$ & 0.039 & 1 (4 \%) & 1 (4.2\%) & ns & $1(4 \%)$ & $6(28.6 \%)$ & 0.036 \\
\hline$\geq 85$ & 23 (95.8 \%) & 15 (71.4\%) & & 24 (96 \%) & 23 (95.8 \%) & & 24 (96 \%) & 15 (71.4\%) & \\
\hline
\end{tabular}

Data are presented as number (ratio) or mean (SD). Significant differences between groups $(p<0.05$, Chi-square test for comparing ratios, Wilcoxon test for comparing scores)

only one child had a score less than 85 in group A, compared with six children in group B. There was also a significant difference in the average scores of groups A and B. The Brunet Lézine results of the control group, who were exclusively breast-fed, were compared with both formula groups: group A and the control group had a similar proportion of children with a score less than 85 and similar average scores. However, group B had worse results than the control group for both proportion of children with a score less than 85 and average score.

\section{Lipid profile}

Some samples were not taken during follow-up due to parental refusal (one at 1 week, five at 3 and 6 months each, and three at 12 months of age). Children from group A had the following results compared with group B (Table 4): significantly higher total levels of $\omega-6$, AA, and PUFA at 6 and 12 months corrected age; significantly higher levels of DHA and $\omega-3$ at 6 months; and similar plasma $\omega-6 / \omega-3$ ratio at 3,6 , and 12 months of age. There were no significant differences in docosapen-

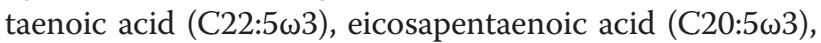

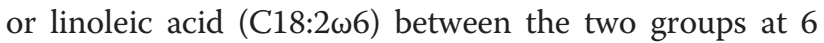
or 12 months.

\section{Anthropometric measurement and evoked potentials}

There were no significant differences between the two groups for the variables of weight, length, or head circumference, during the first two years of life. Likewise, there were no statistically significant differences in the results of visual- and brainstem auditory-evoked potentials at 6 and 12 months corrected age (Table 5).

\section{Discussion and conclusions}

This trial studied very preterm infants who received supplementary formulas with different AA/DHA ratios (group A, 2/1 and group B, 1/1). Group A had significantly higher plasma values of arachidonic acid and polyunsaturated fatty acids than group B. Group A also achieved a higher average Brunet Lézine score at 24 months than group $B$.

Regarding Brunet Lézine score at 24 months, there was a statistically significant difference between the two groups: in group A $(\omega-6 / \omega-3=2 / 1)$, only $4.2 \%$ had a score less than 85. Also, group A had a higher mean score than group B. This could have been due to the higher quantity of $\omega-6$ or PUFAs that group A were fed, as well as the higher plasma levels of $\omega-6$ and PUFAs in group A compared with group B. To explain these results, it must be remembered that AA is a key component of cell membranes, serves as a precursor to prostaglandin formation, and is clearly involved in the signalling systems of the brain [15]. Whilst it is acknowledged that maternal milk is the ideal milk and generally contains a higher concentration of AA than formula milk $[8,28,29]$, the amount of AA needed by preterm infants to maintain ideal brain development is not clear, and more studies and further discussion are required. To clarify the results of this study, we reiterate that the two formula groups were randomly assigned, then observed and followed closely during the first two years of life. From the beginning of the study, the two groups had similar gestational ages, weights at birth, APGAR at 5 and $10 \mathrm{~min}$, and incidence of other risk factors that could affect neurodevelopment (e.g., sepsis, intracranial haemorrhage, bronchopulmonary dysplasia). The study aimed to provide similar nutrition to all preterm infants in the two groups during this period. The two study groups were also compared to a breast milk-only group. However, the two study formulas differed not only in the proportion of omega 6 and omega 3 LCPUFAs, but also in the total amount of LCPUFAs. It cannot be excluded that the better performance of infants fed with formula A could be attributable to the total quantity (and not the ratio) of LCPUFAs.

International groups have published recommendations for the optimal levels of $\omega-3$ and $\omega-6$ during the first three years of life, with recommended $\omega-3$ supplementation ranging from $0.6 \%$ to $2 \%$ of daily energy requirements compared with $5 \%-10 \%$ of $\omega-6$ (almost a 10-fold difference) [24] The European Society for Paediatric Gastroenterology, Hepatology and Nutrition (ESPGHAN) Committee on Nutrition suggests that the daily intake for a preterm infant include the following: DHA, 12 to $30 \mathrm{mg} / \mathrm{kg}(\approx 0.2 \%-0.5 \%$ of all fatty acids $)$ and AA, 18 to $42 \mathrm{mg} / \mathrm{kg}(\approx 0.3 \%-0.7 \%$ of all fatty acids) [25].

Multiple studies have confirmed the importance of PUFAs in preterm infants' mental development and have reported that preterm infants fed with supplemental PUFAs 
Table 4 Comparison of fatty acids in plasma in very preterm infants between two sample groups

\begin{tabular}{|c|c|c|c|c|c|c|c|c|}
\hline \multirow{4}{*}{$\begin{array}{l}\text { Concentration in plasma (\% of } \\
\text { weight of total lipids) }\end{array}$} & \multicolumn{2}{|l|}{ Birth } & \multicolumn{2}{|l|}{3 months } & \multicolumn{2}{|l|}{6 months } & \multicolumn{2}{|l|}{12 months } \\
\hline & $\omega-6 / \omega-3=2$ & $\omega-6 / \omega-3=1$ & $\omega-6 / \omega-3=2$ & $\omega-6 / \omega-3=1$ & $\omega-6 / \omega-3=2$ & $\omega-6 / \omega-3=1$ & $\omega-6 / \omega-3=2$ & $\omega-6 / \omega-3=1$ \\
\hline & Group A $(n=24)$ & Group A $(n=20)$ & Group A $(n=22)$ & Group B $(n=18)$ & Group A $(n=22)$ & Group B $(n=18)$ & Group A $(n=24)$ & Group B $(n=18)$ \\
\hline & Mean (SD) & Mean (SD) & Mean (SD) & Mean (SD) & Mean (SD) & Mean (SD) & Mean (SD) & Mean (SD) \\
\hline \multicolumn{9}{|l|}{ Saturated fatty acids } \\
\hline $\mathrm{C} 12: 0$ & $1.38(0.88)$ & $1.02(0.55)$ & $2.89(1.75)$ & $1.17(0.45)^{*}$ & $5.05(1.85)$ & $3.62(1.51)$ & $3.72(1.08)$ & $4.35(1.19)$ \\
\hline C14:0 & $1.40(0.52)$ & $1.34(0.52)$ & $1,90(0.65)$ & $1.17(0.15)^{*}$ & $2.03(0.36)$ & $1.88(0.35)$ & $1.74(0.31)$ & $1.94(0.38)$ \\
\hline C15:0 & $0.63(0.48)$ & $0.48(0.28)$ & $0.43(0.21)$ & $0.49(0.22)$ & $0.46(0.14)$ & $0.42(0.17)$ & $0.45(0.25)$ & $0.37(0.14)$ \\
\hline C16:0 & $21.78(2.17)$ & $23.70(3.44)$ & $19.86(2.78)$ & $20.33(1.08)$ & $19.94(1.05)$ & $21.01(0.77)$ & $19.77(1.00)$ & $19.59(0.85)$ \\
\hline C17:0 & $0.51(0.14)$ & $0.48(0.14)$ & $0.46(0.11)$ & $0.45(0.11)$ & $0.35(0.11)$ & $0.36(0.08)$ & $0.38(0.11)$ & $0.34(0.08)$ \\
\hline C18:0 & $8.33(1.33)$ & $8.24(1.43)$ & $8.50(1.12)$ & $8.24(0,79)$ & $7.25(0.86)$ & $7.39(0.70)$ & $7.31(0.94)$ & $6.73(0.89)$ \\
\hline C20:0 & $0.27(0.10)$ & $0.23(0.13)$ & $0.20(0.08)$ & $0.28(0.05)^{*}$ & $0.14(0.05)$ & $0.18(0.06)$ & $0.21(0.04)$ & $0.24(0.04)$ \\
\hline C22:0 & $0.90(0.34)$ & $1.08(0.35)$ & $0.70(0.46)$ & $0.58(0.07)$ & $0.60(0.14)$ & $0.56(0.05)$ & $0.55(0.09)$ & $0.54(0.09)$ \\
\hline C23:0 & $0.04(0.03)$ & $0.03(0.01)$ & $0.03(0.02)$ & $0.03(0.03)$ & $0.01(0.01)$ & $0.02(0.01)$ & $0.01(0.01)$ & $0.01(0.00)$ \\
\hline C24:0 & $0.44(0.13)$ & $0.40(0.12)$ & $0.34(0.10)$ & $0.38(0.06)$ & $0.42(0.16)$ & $0.39(0.08)$ & $0.45(0.13)$ & $0.39(0.10)$ \\
\hline C26:0 & $0.00(0.00)$ & $0.00(0.00)$ & $0.00(0.00)$ & $0.00(0.00)$ & $0.00(0.01)$ & $0.00(0.00)$ & $0.00(0.00)$ & $0.00(0.00)$ \\
\hline SFA & $35.69(4.24)$ & $36.99(4.78)$ & $35.31(3.49)$ & $33.13(1.86)$ & $36.26(1.59)$ & $35.68(1.40)$ & $34.58(1.25)$ & $34.50(1.49)$ \\
\hline \multicolumn{9}{|l|}{ Monounsaturated fatty acids } \\
\hline C14:1 $1 \omega 5$ & $0.34(0.23)$ & $0.20(0.07)$ & $0.35(0.23)$ & $0.19(0.17)$ & $0.17(0.11)$ & $0.17(0.09)$ & $0.12(0.04)$ & $0.09(0.01)$ \\
\hline$C 16: 1 \omega 7$ & $3.39(1.67)$ & $4.64(2.48)$ & $1.86(2.48)$ & $1.02(0.41)$ & $0.77(0.22)$ & $1.03(0.40)$ & $1.10(0.30)$ & $0.98(0.34)$ \\
\hline C18:1w9 (t) & $0.24(0.13)$ & $0.23(0.11)$ & $0.27(0.13)$ & $0.24(0.05)$ & $0.18(0.06)$ & $0.19(0.05)$ & $0.18(0.04)$ & $0.17(0.05)$ \\
\hline C18:1w9 (c) & $24.78(2.99)$ & $26.30(3.36)$ & $25.39(2.17)$ & $26.50(2.63)$ & $22.97(1.90)$ & $24.62(2.02)$ & $22.03(2.13)$ & $25.06(2.52)^{*}$ \\
\hline$C 18: 1 \omega 7$ & $0.59(1.02)$ & $0.49(0.81)$ & $0.31(0.62)$ & $0.14(0.09)$ & $0.16(0.19)$ & $0.36(0.50)$ & $0.11(0.03)$ & $0.14(0.11)$ \\
\hline$C 20: 1 \omega 9$ & $0.11(0.25)$ & $0.05(0.01)$ & $0.05(0.04)$ & $0.07(0.03)^{*}$ & $0.050 .02)$ & $0.05(0.01)$ & $0.05(0.01)$ & $0.05(0.01)$ \\
\hline$C 22: 1 \omega 9$ & $0.07(0.03)$ & $0.08(0.03)$ & $0.05(0.02)$ & $0.06(0.02)$ & $0.05(0.02)$ & $0.05(0.02)$ & $0.04(0.02)$ & $0.05(0.01)$ \\
\hline$C 24: 1 \omega 9$ & $1.08(0.33)$ & $1.26(0.36)$ & $0.90(0.34)$ & $0.96(0.41)$ & $0.70(0.17)$ & $0.87(0.19)^{*}$ & $0.77(0.18)$ & $0.88(0.18)$ \\
\hline MUFA & $30.60(3.77)$ & $33.25(4.89)$ & $29.18(3.74)$ & $29.17(2.53)$ & $25.04(1.86)$ & $27.35(1.71)^{*}$ & $24.40(1.90)$ & $27.42(2.53)^{*}$ \\
\hline \multicolumn{9}{|l|}{ Polyunsaturated fatty acids } \\
\hline $\mathrm{C} 18: 2 \omega 6(\mathrm{t})$ & $0.12(0.07)$ & $0.11(0.05)$ & $0.12(0.05)$ & $0.13(0.02)$ & $0.15(0.13)$ & $0.11(0.04)$ & $0.12(0.04)$ & $0.10(0.01)^{*}$ \\
\hline C18:2w6 (c) & $19.89(8.41)$ & $16.57(9.27)$ & $23.36(5.56)$ & $26.43(2.18)$ & $26.75(1.99)$ & $26.91(1.63)$ & $28.22(1.74)$ & $27.68(1.66)$ \\
\hline C18:3w6 & $1.36(0.92)$ & $1.42(0.91)$ & $0.91(0.63)$ & $1.36(0.77)$ & $1.06(0.62)$ & $1.64(0.74)$ & $1.48(0.73)$ & $1.69(0.57)$ \\
\hline C18:3w3 & $0.98(1.07)$ & $0.84(0.98)$ & $0.82(0.28)$ & $0.95(0.18)$ & $0.69(0.16)$ & $0.84(0.08)^{*}$ & $0.71(0.17)$ & $0.91(0.13)^{*}$ \\
\hline$C 20: 2 \omega 6$ & $0.10(0.06)$ & $0.08(0.04)$ & $0.09(0.08)$ & $0.10(0.05)$ & $0.08(0.04)$ & $0.12(0.09)$ & $0.08(0.01)$ & $0.07(0.01)$ \\
\hline$C 20: 3 \omega 9$ & $0.10(0.03)$ & $0.10(0.04)$ & $0.09(0.03)$ & $0.09(0.03)$ & $0.06(0.02)$ & $0.05(0.03)$ & $0.00(0.00)$ & $0.00(0.01)$ \\
\hline
\end{tabular}


Table 4 Comparison of fatty acids in plasma in very preterm infants between two sample groups (Continued)

\begin{tabular}{|c|c|c|c|c|c|c|c|c|}
\hline$C 20: 3 \omega 6$ & $1.45(0.39)$ & $1.57(0.55)$ & $1.14(0.29)$ & $1.44(0.42)^{*}$ & $0.69(0.20)$ & $0.82(0.27)$ & $0.87(0.18)$ & $0.90(0.18)$ \\
\hline C20:4w6 & $7.20(1.75)$ & $6.80(1.57)$ & $6.56(1.29)$ & $4.77(1.09)^{*}$ & $6.74(0.88)$ & $4.22(1.16)^{*}$ & $6.95(1.55)$ & $4.55(0.78)^{*}$ \\
\hline$C 20: 5 \omega 3$ & $0.16(0.13)$ & $0.10(0.14)$ & $0.12(0.10)$ & $0.11(0.10)$ & $0.06(0.07)$ & $0.06(0.07)$ & $0.02(0.01)$ & $0.02(0.01)$ \\
\hline$C 22: 4 \omega 6$ & $0,37(0.12)$ & $0.37(0.07)$ & $0.29(0.07)$ & $0.28(0.05)$ & $0.28(0.06)$ & $0.29(0.05)$ & $0.38(0.07)$ & $0.31(0.08)$ \\
\hline$C 22: 5 \omega 6$ & $0.05(0.04)$ & $0.07(0.05)$ & $0.07(0.10)$ & $0.05(0.02)$ & $0.04(0.01)$ & $0.04(0.02)$ & $0.04(0.01)$ & $0.04(0.01)$ \\
\hline$C 22: 5 \omega 3$ & $0.05(0.03)$ & $0.05(0.03)$ & $0.04(0.02)$ & $0.05(0.02)^{*}$ & $0.05(0.02)$ & $0.05(0.02)$ & $0.06(0.02)$ & $0.06(0.02)$ \\
\hline$C 22: 6 \omega 3$ & $1.89(0.65)$ & $1.70(0.47)$ & $1.90(0.37)$ & $1.93(0.25)$ & $2.05(0.37)$ & $1.66(0.29)^{*}$ & $2.02(0.51)$ & 1.67 (0.38) \\
\hline Total $\omega 6$ & $30.54(6.73)$ & $26.97(8.12)$ & $32.55(5.53)$ & $34.56(1.80)$ & $36.76(2.54)$ & $34.15(1.61)^{*}$ & $38.14(2.21)$ & $35.34(2.43)^{*}$ \\
\hline Total w3 & $3.07(0.88)$ & $2.68(0.79)$ & $2.87(0.50)$ & $3.04(0.29)$ & $2.84(0.33)$ & $2.62(0.28)^{*}$ & $2.81(0.42)$ & $2.67(0.39)$ \\
\hline$\omega-6 / \omega-3$ & $10.41(2.91)$ & $10.30(2.25)$ & $11.5(1.9)$ & $11.4(1.2)$ & $12.7(1.7)$ & $13.2(1.2)$ & $13.9(2.7)$ & $13.5(2.5)$ \\
\hline PUFA & $33.71(7.27)$ & $29.75(8.77)$ & 35.51 (5.78) & $37.69(1.87)$ & $38.69(2.52)$ & $36.82(1.81)^{*}$ & $41.02(2.09)$ & $38.08(2.32)^{*}$ \\
\hline
\end{tabular}

Data are presented as mean (SD). *Significant differences between groups $(p<0.05$, Wilcoxon test) 
Table 5 Comparison of somatic growth and evoked potentials between two sample groups

\begin{tabular}{|c|c|c|c|c|}
\hline \multirow{3}{*}{$\begin{array}{l}\text { Comparison of somatic growth and } \\
\text { evoked potentials between two } \\
\text { groups }\end{array}$} & & \multirow{3}{*}{$\begin{array}{l}\omega-6 / \omega-3=2 \text { Group A } \\
n=24(12 \mathrm{M} \text { and } 12 \mathrm{~F}) \\
\text { Mean (SD) }\end{array}$} & \multirow{3}{*}{$\begin{array}{l}\omega-6 / \omega-3=1 \text { Group B } \\
n=21(10 \mathrm{M} \text { and } 11 \mathrm{~F}) \\
\text { Mean (SD) }\end{array}$} & \multirow{3}{*}{$\begin{array}{l}P \\
\text { value }\end{array}$} \\
\hline & & & & \\
\hline & & & & \\
\hline \multirow[t]{6}{*}{ Weight (g) } & At birth $M$ & $1460(355)$ & $1254(362)$ & ns \\
\hline & At birth F & $1287(228)$ & $1154(176)$ & ns \\
\hline & At 12 months $\mathrm{M}$ & $9233(989)$ & $9276(2053)$ & ns \\
\hline & At 12 months $F$ & 8368 (1408) & $7040(711)$ & ns \\
\hline & At 24 months $M$ & $12192(1218)$ & 12295 (1878) & ns \\
\hline & At 24 months $F$ & 11038 (2503) & 9979 (956) & ns \\
\hline \multirow[t]{6}{*}{ Length $(\mathrm{cm})$} & At birth $M$ & $40.6(3.6)$ & $39.1(2.8)$ & ns \\
\hline & At birth $F$ & $38.4(1.2)$ & $36,4(1.7)$ & ns \\
\hline & At 12 months $M$ & $74.1(2.7)$ & $73.6(5.8)$ & ns \\
\hline & At 12 months $F$ & $69.8(3.1)$ & $68.4(0.9)$ & ns \\
\hline & At 24 months $M$ & $86.1(2.7)$ & $84.9(4.1)$ & ns \\
\hline & At 24 months $F$ & $82.9(3.1)$ & $81.7(2,9)$ & ns \\
\hline \multirow[t]{7}{*}{ Head circumference $(\mathrm{cm})$} & At birth $M$ & $28.4(1.7)$ & $27.5(2.1)$ & ns \\
\hline & At birth F & $27.6(1.9)$ & $27.1(1.8)$ & ns \\
\hline & At 12 months $\mathrm{M}$ & $45.7(1)$ & $45.9(1.5)$ & ns \\
\hline & At 12 months $F$ & $45.3(1.7)$ & $45.1(1.1)$ & ns \\
\hline & At 24 months $M$ & $48.6(1)$ & $48.4(1.8)$ & ns \\
\hline & At 24 months $F$ & $47.9(1.7)$ & $48(0.8)$ & ns \\
\hline & & $\%$ normal & $\%$ normal & \\
\hline \multirow[t]{2}{*}{ Visual-evoked potentials } & At 6 months & $92 \%$ & $81 \%$ & ns \\
\hline & At 12 months & $96 \%$ & $86 \%$ & ns \\
\hline \multirow[t]{2}{*}{ Brainstem auditory-evoked potentials } & At 6 months & $79 \%$ & $86 \%$ & ns \\
\hline & At 12 months & $83 \%$ & $90 \%$ & ns \\
\hline
\end{tabular}


(especially DHA) showed improved brain development. However, none of these trials clearly recommended an $\omega-6$ to $\omega-3$ ratio $[11,12,26]$.

A review of the scientific literature showed that the AA/DHA ratio in formula milk (often 1/1) is different from the AA/DHA ratio in breast milk. In a review of 65 studies involving 2474 women, the mean concentration of DHA in breast milk was $0.32 \%$ (range: $0.06 \%-1.4 \%$ ) and that of AA was $0.47 \%$ (range: $0.24 \%-1.0 \%$ ) [27]. In a study on FA composition of mothers' milk at 3, 7, and 28 days post-partum in term and preterm infants, the ratio of AA/DHA was approximately $3 / 1$ and $2 / 1$, respectively, with DHA levels between 0.5 \%-1.0 \%, and AA levels between $1.3 \%-2.6 \%$ [28]. Also, in one investigation conducted in nine countries concerning breast milk for term neonates, 7 countries reported an AA/ DHA ratio greater than $1 / 1$ and only 2 countries reported a ratio of less than $1 / 1$ (range, from $0.51 / 1$ in Japan to 3.16/1 in the USA) [29]. In a new study of term infants in the USA, the AA/DHA ratio in breast milk was $2.64 / 1$ at birth and $2.81 / 1$ at 6 weeks [8].

Interestingly, despite having different formula ratios of AA/DHA, the same quantity of DHA, and almost the same proportion of mixed-fed children (breast-fed with formula) in groups A and B, there was almost no difference between the two groups in plasma $\omega-6 / \omega-3$ ratio and group A had higher DHA levels than group B at 6 months. This could have been because $\alpha$-Linolenic acid and Linoleic acid compete for the same enzyme pathways to form DHA and AA, respectively [30], and since group A had higher AA supplementation, the internal balance of LCPUFA synthesis could have shifted towards DHA. In addition, plasma omega-6/omega-3 ratios were not expected to be similar, and this result could have been because omega- 6 and omega- 3 have many components besides AA and DHA. The balance of omega- 6 and omega- 3 is highly complex, and our trial is the first in addressing AA, as previous trials have focused on DHA and overlooked AA. Therefore, further studies are required to understand the complex relationship between omega- 6 and omega-3. However, plasma PUFAs were higher in group A than in group B. This means that the increased quantity of AA in the milk given did not affect the balance between $\omega-6$ and $\omega-3$. This balance is considered very important in human health and growth [9].

A recent review showed that LC-PUFA supplementation during pregnancy was associated with modest increases in birth size in both low-income and highincome populations. However, postnatal supplementation with LC-PUFAs did not influence infant growth [31]. Throughout our study, anthropometric growth was measured during the first two years of life in groups A and $\mathrm{B}$, and weight, height, and head circumference growth were similar in the two groups. Therefore, these results suggest that higher formula levels of omega- 6 do not affect anthropometric growth.

The VEP results of group A and group B were compared, showing no major differences in visual function, a result that supports the unique importance of DHA in visual pathway maturation in preterm infants. Underscoring this, DHA levels have been shown to reach $30 \%-40 \%$ of total fatty acids in rod photoreceptor outer segments of the human retina [32] and the two formula groups received the same quantity of DHA. This result was despite of the different plasma DHA values at 6 months.

Theoretically, the auditory tracts are neural fibres, and LC-FUFAs are thought to be important in their development and maturation. However, no studies were found to support this hypothesis. Paradoxically, one study showed no effect of LC-PUFA on auditory brain-stem evoked responses [33]. Due to the above data, no important differences were anticipated between the two groups in terms of auditory function, despite one group having double the quantity of AA.

All mothers were from the same geographical area, were of the same ethnicity and religion, and had similar dietary habits. There are several studies on the omega-6/ omega-3 ratio in breast milk confirming minimal differences in this ratio in the same geographical region, and marked differences only between distant parts of the world, because of distinct dietary habits $[27,29]$. Therefore, in this study, the breast milk omega-6/omega-3 ratio was not measured, as it was understood that it would contain a similar ratio, and that the significant difference in the omega-6/omega- 3 ratio was between the supplemental formulas only. Also, the number of mixed-fed babies decreased significantly after the first month of life (from the first month to the third month, from $54 \%$ to $21 \%$ in group A and from $48 \%$ to $24 \%$ in group B).

There was a variety of factors that were difficult to control, for example the socio-economic status and the educational level of the mother [34,35]. These factors could have played an important role in neurodevelopment and cognitive function. Finally, the relatively small sample sizes (as a result of more children than expected being lost to follow-up) could be another limitation of this trial.

In conclusion, the improved LCPUFA plasma concentrations and psychomotor development in very preterm infants despite the same formula quantity of DHA could have been due to the double mount ratio of AA to DHA or the higher total quantity of LCPUFAs. Nevertheless, further studies are required to support the benefits of a balanced AA/DHA ratio (more AA) in preterm infant supplementation.

\section{Abbreviations}

AA: Arachidonic acid; DHA: Docosahexaenoic acid; GA: Gestational Age; LCPUFA: Long chain polyunsaturated Fatty Acids; VLBW: Very low birth weight; $\omega$-3: Omega 3; $\omega$-6: Omega 6. 


\section{Competing interests}

The authors declare that they have no competing interests. All authors have made substantial contributions to the conception and design of the study and each author has seen and approved the contents of the submitted manuscript.

\section{Authors' contributions}

$A M, J F$ and MLC were responsible for conception and study design. AM and $A B$ were responsible for recruitment and study visits. $F A$ and $L A$ were responsible for the coordination in Bilbao. AA performed sample analysis, AA and AM were responsible for statistical analyses, and AA, MJD, and MLC interpreted the data. AA, MSP, and MLC wrote the manuscript, and all authors critically reviewed the manuscript. All authors read and approved the final manuscript.

\section{Acknowledgements}

Health Research Institute of Santiago (IDIS)

Neurophysiology Unit, University Clinical Hospital of Santiago de Compostela.

Early Care Unit, University Clinical Hospital of Santiago de Compostela.

\section{Author details}

${ }^{1}$ Neonatology Unit, Department of Paediatrics, University Clinical Hospital of Santiago de Compostela. IDIS, CIBERER, Travesia Choupana, 15706, Santiago de Compostela, Spain. ${ }^{2}$ Motabolism Group, BioCruces Health Research Institute, CIBER of Rare Diseases (CIBERER), Plaza de Cruces 12, 48903 Baracaldo, Vizcaya, Spain. ${ }^{3}$ Neonatology Unit, Department of Paediatrics, La Paz University Clinical Hospital, P de la Castellana 261, 28064 Madrid, Spain.

Received: 21 July 2015 Accepted: 22 September 2015 Published online: 30 September 2015

\section{References}

1. Gould JF, Smithers LG, Makrides M. The effect of maternal omega-3 LCPUFA supplementation during pregnancy on early childhood cognitive and visual development: a systematic review and meta-analysis of randomized controlled trials. Am J Clin Nutr. 2013;97:531-44.

2. Willatts P, Forsyth S, Agostani C, Casaer P, Riva E, Boehm G. Effects of long chain PUFA supplementation in infant formula on cognitive function in later childhood. Am J Clin Nutr. 2013;98(Suppl):536S-42S.

3. Jiao J, Li Q, Chu J, Zeng W, Yang M, Zhu S. Effect of n-3 PUFA supplementation on cognitive function throughout the life span from infancy to old age: a systematic review and meta-analysis of randomized controlled trials. Am J Clin Nutr. 2014;100(6):1422-36. doi:10.3945/ ajen.114.095315.

4. Riediger ND, Othman RA, Suh M, Moghadasian MH. A systemic review of the roles of $\mathrm{n}-3$ fatty acids in health and disease. Journal of the American Dietetic Association. 2009;109:668-79.

5. Sabel KG, Lundqvist-Persson C, Bona E, Petzold M, Strandvik B. Fatty acid patterns early after premature birth, simultaneously analyzed in mothers' food, breast milk and serum phospholipids of mothers and infants. Lipids Health Dis. 2009;8:20

6. Innis SM. Dietary (n-3) fatty acids and brain development. J Nutr. 2007;137(4):855-9.

7. Qawasmi A, Landeros-Weisenberger A, Leckman JF, Bloch MH. Meta-analysis of long-chain poly unsaturated fatty acid supplementation of formula and infant cognition. Pediatrics. 2012;129:1141-9.

8. CL S n, Oliver JS, Marriage BJ. Docosahexaenoic acid supplementation in lactating women increases breast milk and plasma docosahexaenoic acid concentrations and alters infant omega 6:3 fatty acid ratio. Prostaglandins Leukot Essent Fatty Acids. 2015;95:63-9. doi:10.1016/j.plefa.2015.01.005

9. Innis SM. Human milk and formula fatty acids. J Pediatr. 1992;120:S56-61

10. Anderson JW, Johnston BM, Remley DT. Breast feeding and cognitive development: a meta-analysis. Am J Clin Nutr. 1999;70:525-35.

11. Arterburn L, Bailey Hall $E$, Oken $H$. Distribution, and dose response of $n-3$ fatty acids in humans. Am J ClinNutr 2006:83(Suppl.):1467S-1476S.

12. Clandinin MT, Van Aerde JE, Merkel KL. Growth and development of preterm infants fed infant formulas containing docosahexaenoic acid and arachidonic acid. J Pediatr. 2005;146(4):461-8.
13. O'Connor DL, Hall R, Adamkin D, Auestad N, Castillo M, Connor WE. Growth and development in preterm infants fed long-chain polyunsaturated fatty acids: a prospective, randomized controlled trial. Pediatrics. 2001;108(2):359-71.

14. Meldrum SJ, D'Vaz N, Simmer K, Dunstan JA, Hird K, Prescott SL. Effect of high dose fish oil supplementation during earlyinfancy on neurodevelopment and language: a randomized controlled trial. Br J Nutr. 2012:108:1443-54.

15. Fukaya T, Gondaira T, Kashiyae Y, Kotani S, Ishikura Y, Fujikawa S, et al. Arachidonic acid preserves hippocampal neuron membrane fluidity in senescent rats. Neurobiol Aging. 2007;28(8):1179-86.

16. Wang ZJ, Liang CL, Li GM, Yu CY, Yin M. Neuroprotective effects of arachidonic acid against oxidative stress on rat hippocampal slices. Chem Biol Interact. 2006;163(3):207-17.

17. Darios F, Davletov B. Omega-3 and omega- 6 fatty acids stimulate cell membrane expansion by acting on syntaxin 3. Nature. 2006:440(7085):813-7.

18. Birch Eileen E, Garfield S, Hoffman Dennis R, Uauy R, Birch David G. A randomized controlled trial of early dietary supply of long-chain polyunsaturated fatty acids and mental development in term infants. Dev Med Child Neurol. 2007:42(3):174. doi:10.1111/j.1469-8749.2000.tb00066.

19. Muller H, Kirkhus B, Pedersen J. Serum cholesterol predictive equations with special emphasis on trans and saturated fatty acids. Analysis from designed controlled studies. Lipids. 2001;36:783-91.

20. Simopoulos AP. Genetic variants in the metabolism of omega- 6 and omega-3 fatty acids: their role in the determination of nutritional requirements and chronic disease risk. Exp Biol Med. 2010;235:785-95.

21. Bauer J, Gerss J. Longitudinal analysis of macronutrients and minerals in human milk produced by mothers of preterm infants. Clin Nutr. 2011:30(2):215-20.

22. Lepage G, Roy CC. Direct transesterification of all classes of lipids in a onestep reaction. J Lip Res. 1986;27:114-20.

23. Brunet O, Lézine I, Josse D. Brunet-Lézine Révisé: échelle de développement psychomoteur de la première enfance. Paris: Manuel BLR-C; 1997.

24. Otten JJ, Hellwig JP, Meyers LD. Institute of Medicine: dietary reference intakes: the essential guide to nutrient requirements. Washington, DC: National Academies Press; 2006

25. Agostoni C, Buonocore G, Carnielli VP. Enteral nutrient supply for preterm infants: commentary from the European Society of Paediatric Gastroenterology, Hepatology and Nutrition Committee on Nutrition. J Pediatr Gastro Eenterol Nutr. 2010;50:85.

26. Colombo J, Carlson SE, Cheatham CL, Shaddy DJ, Kerling EH, Thodosoff JM, et al. Long-term effects of LCPUFA supplementation on childhood cognitive outcomes. Am J Clin Nutr. 2013;98:403-12.

27. Brenna JT, Varamini B, Jensen RG, Diersen-Schade DA, Boettcher JA, Arterburn LM. Docosahexaenoic and arachidonic acid concentrations in human breast milk worldwide. Am J Clin Nutr. 2007;85:1457-64.

28. Aydin I, Turan Ö, Aydin FN, Koç E, Hirfanoğlu IM, Akyol M, et al. Comparing the fatty acid levels of preterm and term breast milk in Turkish women. Turk J Med Sci. 2014:44:305-10.

29. Yuhas R, Pramuk K, Eric L, Lien EL. Human milk fatty Acid composition from nine countries varies most in DHA. Lipids. 2006;41:851-8.

30. Bradbury J. Docosahexaenoic acid (DHA): an ancient nutrient for the modern human brain. Nutrients. 2011;3(5):529-54.

31. Makrides M, Collins CT, Gibson RA. Impact of fatty acid status on growth and neurobehavioural development in humans. Maternal and Child Nutrition. 2011:7(2):80-8

32. Ricardo $U$, Hoffman DR. Essential fat requirements of preterm infants. Am J ClinNutr. 2000;71(suppl):245S-50S

33. Faldella G, Govoni M, Alessandroni R, Marchiani E, Salvioli GP, Biagi PL, et al. Visual evoked potentials and dietary long chain polyunsaturated fatty acids in preterm infants. Arch Dis Child. 1996;75:F108-12.

34. Braveman PA, Heck K, Egerter S, Marchi KS, Dominguez TP. The role of socioeconomic factors in Black-White disparities in preterm birth. Am J Public Health. 2015;105(4):694-702.

35. Rahkonen P, Heinonen K, Pesonen AK, Lano A, Autti T. Mother-child interaction is associated with neurocognitive outcome in extremely low gestational age children. Scand J Psychol. 2014;55(4):311-8. 